\title{
QUADRO CLINICO DO LOBO ORBITÁRIO COM CRISES CEREBELARES: CISTICERCOSE RACEMOSA DO ÂNGULO PONTO-CEREBELAR
}

\author{
Anibal Silveira* \\ MÁrio Robortella ** \\ WALTER E. MAFFEI ***
}

Intenta a presente observação clinica evidenciar uma vez mais a correlação entre distúrbios funcionais e alterações orgânicas do cérebro, o que sómente pode ser compreendido-à luz da patogenia dos sintomas.

O paciente em aprêço foi apresentado primeiramente em conferência clínica de caráter prático, na Enfermaria do $4 .^{\circ}$ Pavilhão Masculino (março de 1945) a fim de mostrar-se o fundamento do diagnóstico diferencial entre pitiatismo e alterações cerebrais objetivas. Posteriormente - junho de 1945 - ainda com finalidade idêntica e como demonstração prática, porém já em reunião do Centro de Estudos Franco da Rocha, dQis dos atuais autores (A. S. e M. R.) discutiram em pormenores o feitio do quadro clínico em causa, procurando estabelecer os dados localizatórios e a patogenia das manifestaçōes neuropsiquiátricas ${ }^{18}$. A observação clínica que a seguir apresentamos corresponde à redação de todos os dados neuropsiquiátricos coligidos até a época da última comunicação há pouco mencionada e revistos quanto à evolução até a data em que se deu o óbito.

\section{OBSERVAÇAO}

G.P.M., brasileiro, viúvo, com 43 anos de idade ao ser admitido no Hospital de Juqueri, a 12-1-1945 (R.G. 29.759), falecido a 14-12-1945.Súmula do exame procedido no ato de entrada (Dr. Darcy Uchoa): Más condiçōes físicas. Refere que tivera "congestão" e depois ficou com fraqueza nas pernas (sic). Além disso "é muito atrapalhado da cabeça", "ouvindo muita conversa". Desorientação quanto ao lugar e ao tempo.

Súmula dos dados neuropsiquiátricos em março de 1945****: O paciente informa corretamente o próprio nome, a idade, a data de admissão. Desorientado quanto ao local e parcialmente quanto ao motivo da internação, bem como em relação ao próprio estado mórbido. Refere com satisfatória precísão datas, fatos e indivi-

Trabalho realizado no Hospital de Juqueri e apresentado em reunião do Centro de Estudos "Franco da Rocha" a 22-11-1946. Na época os autores exerciam no Hospital de Juqueri os seguintes cargos: * Chefe de Clínica (1* Secção Masculina); ** Psiquiatra-Chefe (49 Pavilhão Masculino); *** Chefe do Laboratório de Anatomia Patológica.

**** A observação psiquiátrica por extenso, a que correspondem êste extrato e os seguintes, acha-se no Arquivo Clínico do Hospital de Juqueri. 
duos relacionados com a própria pessoa. O trabalho mental se processa com acentuada lentidão, porém não se evidenciam distúrbios intrínsecos. A atenção, mesmo voluntária, é pouco fixável. Nega distúrbios senso-perceptivos e não os denota pelo comportamento. Expressão verbal sem transtornos apreciáveis. Indiferente à própria situação. Atitudes por vêzes teatrais, aparentemente pitiáticas. Exame neurológico - Dados de tipo subjetivo inacessiveis pela incapacidade de cooperação do paciente; dados objetivos em parte estáveis, em parte variáveis de sessão para sessão. Amimia constante; "mastigaçāo forçada". Tendência ả imobilidade em geral. Reflexos profundos presentes e simétricos. Hipertonia variável, aparentemente despertada pela atenção durante as manobras de exame. Marcha em pequenos passos com incerteza variável, especialmente quando o paciente é largado pelos auxiliares que o sustinham. Camptocormia, que se exagera nas mesmas condições. Queda por perda lenta do equilibrio e em direção variável. Crises tônicas do tipo da rigidez por descerebração. Condições somáticas - Com relação aos aparelhos de vida vegetativa nada se aprecia atualmente que exija menção especial. As condições relativas ao estado geral todavia são precárias, não só pela evidente impossibilidade de prover à própria alimentação como possivelmente também por desvio intrínseco nos processos de nutricão. Exames subsidiários - Exame neuroftalmológico só possível com relação aos fundos oculares que se apresentavam normais. Exame do líqüido cefalorraquidiano: punção suboccipital, paciente sentado; $0,20 \mathrm{~g}$ de proteinas por litro; reações de Pandy, de Weichbrodt e de Nonne, levemente positivas; $5 / 3$ células por $\mathrm{mm}^{3} ; 575$ hemácias por $\mathrm{mm}^{3}$; reação do benjoim coloidal 01210.12210.00000.0; reação de Wassermann positiva a partír de 0,1 cc. Reacões sorológicas para lues (Wassermann, Kahn e Eagle) negativas.

Diagnóstico clínico provisório - A concomitância de alterações neurológicas permanentes mas pouco precisas, até certo ponto mascaradas por outras de tipo variável e de transtornos mentais que - considerados superficialmente - poderiam interpretar-se como pitiáticos, induziria a pensar em conversão histérica. Todavia o próprio feitio dêsse complexo sintomático levou ao diagnóstico clínico e topográfico que adiante discutiremos e que resumiramos desde o principlo na seguinte rubrica: Psicose por lesão cerebral, com provável comprometimento organico da regicao frontal orbitaria ou da via fronto-ponto-cerebelar.

Quanto à etiologia, a hipótese era de processo preferentemente extracerebral, possiveimente por hipertensão intracraniana variável. A arteriosclerose fôra considerada como pràticamente afastada devido ao exame neuroftalmológico; entretanto nāo se poderia excluir a possibilidade de processos vasculares e mesmo tumorais, - que exigia novas verificações paraclínicas. Nowo exame de liqüido cefalorraquidiano, em maio de 1945, revelou: $0,28 \mathrm{~g}$ de proteínas por litro; reaçōes de Pandy, de Weichbrodt e de Nonne levemente positivas; $7,13 \mathrm{~g}$ de cloretos por litro; 11 células por $\mathrm{mm}^{3}$; reação do benjoim coloidal 12221.22221.00000.0; reação de Takata-Ara positiva, de tipo floculante; reação de Wassermann prefudicada.

Evolução das manifestrções clinicas até junho de $1945^{*}-$ O exame neurológico revelou desde o início fácies amímica, de resto com movimentos de mastigação contínuos, e camptocormia. O equilibrio estava prejudicado; a atitude ereta só era possivel sob o apoio de ambos os lados; quando se suprimia êsse apoio, o paciente caía pesadamente. Sentado, caía para trás, não conseguindo voltar à posição primitiva espontâneamente. Marcha em pequenos passos, recurvado para diante. Mais tarde, mesmo apoiado tinha dificuldade em esboçar a locomoção (disbasia). Freqüentemente era acometido por crises súbitas de hipertonia difusa com perda momentânea da consciência, porém sem convulsões, semelhantes às crises de rigidez por descerebração (cerebeljar fits, de Jackson). Surgiram tremores, especialmente de tipo intencional. Os reflexos profundos têm estado presentes e normaís. Não

* Quando da apresentação do paciente em reunião do Centro de Estudos "Franco da Rocha" ${ }^{18}$. 
cooperava, em geral, para a pesquisa de déficit piramidal, porém nas poucas vêzes em que o estado psiquico a permitiu não se evidenciaram distúrbios dêsse tipo nem sinais outros de alteração cerebelar. Uitimamente vinha apresentando relaxamento dos esfincteres. Com relaçāo aos nervos cranianos havia a assinalar estrabismo interno à direita e paralisia facial direita de tipo central e variável, porém não permanente. Anotamos também espasmo facial durante uma crise hipertônica. Quanto ao estado psíquico, no início apresentava geralmente conservada a capacidade de orientação. Identificava-se, orientava-se em relação à data de internação; entretanto errava completamente ao tentar reconhecer o local. Conservava parcialmente a noção de doença. Repetia com certa precisão algumas datas e alguns fatos, denotando satisfatória capacidade de evocação. Não havia distúrbios apreciáveis de percepção. Com referência ao trabalho mental, fazia-se êste excessivamente moroso, porém não se apuravam deficienncias alógicas do pensamento na acepção de Kleist, nem idéias delirantes. A expressão verbal, isenta de defeitos neurológicos e de desordens peculiares, era lenta, parca e sem mimica facial complementar. A iniciativa para a ação prática e a afetividade estavam grandemente comprometidas. quando das manobras para os exames neurológicos e durante as verificaçōes psiquiátricas os transtornos neurológicos se acentuavam exageradamente: intensificavam-se grandemente os tremores, o paciente assumia atitudes extravagantes devido à hipertonia dos membros inferiores e à camptocormia. Eram freqüentes as quedas em ritmo lento, como que intencionais. Esta particularidade daria a impressão de pitiatismo ao examinador menos avisado.

Evolução ulterior - As condições neurológicas e mentais foram piorando gradativamente, embora por surtos. Assim, decorridos 5 meses a partir da primeira observação, isto é, em agôsto de 1945, o que dominava o quadro psiquiátrico eram a obnubilação, quanto às funçōes intelectuais, e a espurcicia. Pelo aspecto neurológico estavam mais acentuados a impossibilidade de locomoção, a ataxia do tronco, o relaxamento dos esfincteres.

Ncva verificação neuro-oftalmológica nada revelou, ainda esta vez, que fôsse digno de menção. O exame de liquor, repetido então (10-10-1945), trouxe esclarecimentos decisivos quanto à etiologia: punção suboccipital, doente deitado; pressão inicial 23,5; final 6 (manômetro de Claude); $0,50 \mathrm{~g}$ de proteinas por iitro; $7,20 \mathrm{~g}$ de cloretos por Iitro; reações de Pandy, de Weichbrodt e de Nonne positivas; reação do benjoim coloidal 12222.22222.10000.0; reação de Takata-Ara positiva, tipo floculante; 17,4 células por $\mathrm{mm}^{3}$; reação de Wassermann negativa com 1 cc; reação de Steinfeld, positiva; reação para cisticercose, positiva.

Diagnóstico clínico-localizatório - A hipótese diagnóstica inicial pôde assim ser confirmada e mesmo precisada: pelos dados liquóricos, quanto ao fator causal; pelo decurso dos sintomas, com referencia ao significado topistico, isto é, em relação ao sistema encefálico atingido.

Em primeiro lugar, os sintomas neuropsiquiátricos seriam de oriçorn extracortical, mesmo extracerebral, pois as manifestações psiquicas se haviam mostrado variáveis em intensidade e até em amplitude, no decorrer da observação. Além disso os sintomas mentais. como lentidão da fala e periodos de obnubilação, indicavam o comprometimento transitório do lobo frontal. Éste dado era corroborado pela ocorrência de distúrbios neurológicos variáveis mas progressivos: incapacidade para manter a atitude ereta - donde camptocormia - e disbasia. Por outro lado, o fato de não haver incidido apraxia da marcha do tipo da ataxia frontal de Brun mostrava que a convexidade frontal, ao nivel do pólo, estaria indene: os distúrbios teriam então origem ao nivel da zona orbitária. O mesmo raciocinio patogenético se aplicava aos distúrbios cerebelares: a constância e a variação em intensidade induziam a excluir a hipótese de lesão intracortical ou intra-encefálica também a êste nivel. Teriamos a considerar pois um processo não destrutivo, localizado de modo a perturbar por compressão a dinâmica das vias fronto-ponto-cerebelares, especificamente as ligações cerebelo-orbitárias. A apatia, a falência de estímulo para 
contactuar com o ambiente, o desinterésse variável no plano instintivo - comparável ao do histérico ante a dramaticidade do próprio quadro mórbido - - traduziriam a falência do componente orbitário dêste sistema.

A positividade da reação de fixação de complemento para cisticercos, no liquor, veio elucidar a natureza provável de tal processo, a qual suspeitáramos fôsse tumoral, conforme o diagnóstico antes transcrito. Tornou-se patente a existencia de cisticercose em contacto com o sistema liquórico: as vesiculas estariam agindo como massa tumoral. Mesmo que houvesse vesículas intra-encefálicas, não seriam estas a causa dos distúrbios neuropsiquicos. E para produzirem efeitos tão amplos como os mencionados no quadro clínico, deveriam assestar-se ao nivel da porção mais concentrada do sistema trans-hemisférico referido: ao nivel do cerebelo e da ponte.

Estas consideracões quanto ao dinamismo patogênico levaram-nos pois ao diagnóstico localizatório então exarado: quadro neuropsiquiátrico orbitário, como repercussão de alterações ponto-cerebelares; cisticercose provável.

Dados anátomo-patológicos - O doente faleceu em 14 de dezembro de 1945, em caquexia por disenteria amebiana. O exame anátomo-patológico (W.E.M.) mostrou, ao nivel do ângulo ponto-cerebelar direito, um cacho de vesículas de cisticerco, piriformes e destituídas de scólex, portanto com os caracteres do cisticerco racemoso (fig. 1). A leptomeninge estava assaz espessada na base do encéfalo, principalmente em tôrno da protuberância, do pedúnculo cerebral e da cisterna quiasmática, englobando os rervos cranianos; êsse espessamento se continuava pela fenda de Bichat e pela base dos lobos temporais. As artérias da base do encéfalo estavam ligeiramente espessadas. Nos hemisférios cerebrais, ao nivel da convexidade, nada de anormal. Os cortes frontais do cérebro também nada mostraram digno de nota. Encéfalo pesando $1.250 \mathrm{~g}$. Nos demais órgãos notavam-se apenas atrofia e anemia; e no fígado havia também esteatose. $O$ intestino grosso apresentava em tôda a extensâo ulceraçōes da mucosa, de contornos arredondados e de tamanho variado, caracteres êstes da disenteria amebiana. Cortes do cérebro, incluidos em celoidina e corados pelos métodos de Nissl e de Weil nada revelaram digno de menção.

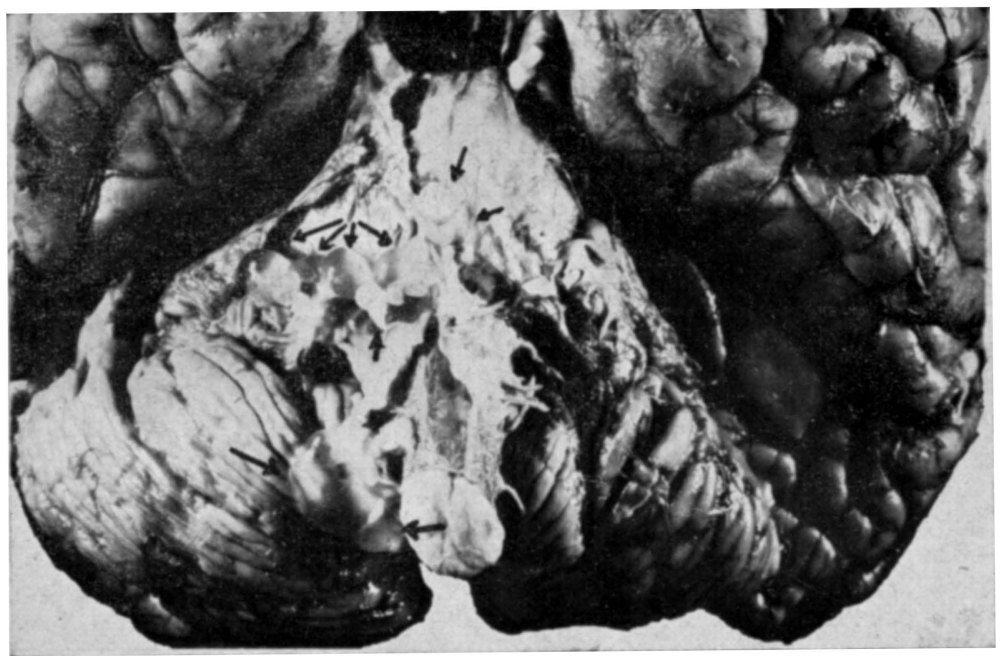

Fig. 1 - G.P.M. Numerosas vesículas de cisticercos ao nivel do ângulo ponto-cerebelar direito (setas). 


\section{COMENTARIOS *}

A presente observação anátomo-clínica parece-nos ilustrativa sob vários aspectos. Antes de mais nada, evidencia que é por vêzes possivel chegar ao diagnóstico topográfico das lesões encefálicas tomando por base apenas os sintomas neuropsiquicos. Isto exige somente que se apreciem tais sintomas à luz da dinâmica cerebral e não pelo prisma da mera descrição. No caso em aprêço, a análise clínica sob êsse critério fêz prever que o quadro orbitário devia depender de processo à distância, cerebelar ${ }^{18}$. Para a eventualidade neurocirürgica, é nossa opinião, semelhante critério se torna fundamental: vale pelo menos para orientar e joeirar os recursos paraclínicos ${ }^{16 c}$.

Outra peculiaridade que merece comentada, a de que sintomas variáveis em intensidade e inconstantes - em aparência pitiáticos - podem resultar de alterações estruturais. O raciocínio médico, entretanto, leva habitualmente a tomar a ambas essas condições como antagônicas. Em relação ao paciente isto sucedeu por mais de uma vez. Quando inicialmente apresentado em reunião clínica semanal do $4 .^{\circ}$ Pavilhão - justamente para frisar êste particular de semiótica - foi considerado como histérico por ilustre psiquiatra do Distrito Federal que visitava o Hospital : a direção inconstante nas quedas, a lentidão e a aparente cautela ao cair, as reações emocionais que exageravam os distúrbios neurológicos ante o nosso exame, levaram aquêle colega a discordar do diagnóstico de lesão do encéfalo. Novamente a hipótese de histeria - pitiatismo a nosso ver, se fôsse o caso foi aventada em reunião clínica do Centro de Estudos ${ }^{18}$ por alguns colegas que na ocasião discordavam de nossa interpretação quanto à patogênese. A topografia e a natureza especial do processo etiológico explicam essa concorrência entre manifestações funcionais e alterações orgânicas, a qual nada tem de fortuita.

Acentuamos alguns dados neurológicos e psíquicos implicados na diagnose diferencial porque exprimem a participação de duas zonas corticais básicas no funcionamento do encéfalo: a cerebelar e a frontal orbitária. Os mediadores fisiológicos dessa cooperação fundamental, as vias fronto-pontocerebelar e cerebelo-hipotalâmico-orbitária, permitem compreender a patogênese do quadro mental ${ }^{14}$, a razão de ser da sucessão dos sintomas frontais secundários ${ }^{16 b}$ e, principalmente, identlficar os distúrbios frontais de repercussão ${ }^{19}$. Na ocorrência clínica resumida na precedente observação psiquiátrica, o conjunto da sintomatologia neuropsíquica e a importância variável dos distúrbios permitiram deduzir que estava perturbado, em sentido eferente, o sistema cerebelo-orbitário.

Efetivamente, na opinião de um dos autores (A. S.), é preciso distinguir naquele grupo de ligações trans-hemisféricas não só o tipo filogenético mas também a direção dos impulsos. O primeiro conjunto de vias cerebelo-frontais agora mencionado seria neo-encefálico, o segundo páleo-encefálico: aquêle,

* Nota da presente publicação - Atemo-nos à reconstituição do comentário e à citação bibliográfica de 1947, sem atualizá-los. 
preposto de preferência ao tono muscular de ação e a funções psiquicas de relação; êste, antes ao tono muscular de atitude e a funções dizentes com a vida vegetativa. Em ambos os casos a direção eferente, ou cerebelifuga, dos impulsos corresponderia ao estímulo da função correspondente; e a direção oposta traduziria o mister de regência. Assim, haverá falência da função correspondente se a lesão se assestar na zona de estímulo e fôr de natureza inibitória ou destrutiva; ocorrerá ao contrário a liberação se ela fôr irritativa ou se estiver ao nivel das áreas de regência. O ef eito considerado na primeira hipótese poderá, entretanto, deixar de manifestar-se, no caso de alteração crônica e principalmente estabelecida na fase inicial de desenvolvimento: é que nessa eventualidade a zona de regência poderá compensar o distúrbio quanto aos aspectos menos diferenciados, então com sacrifício, em geral, das atribuições mais dependentes que lhe são próprias. Exemplificam esta última modalidade clínica os dados de um paciente de 60 anos, que apresentava grave atrofia neocerebelar, presumivelmente desde os 6 meses de idade: nenhum distúrbio cerebelar, mas deficiência mental profunda. A conclusão foi que os lobos frontais, normais, haviam sido desviados da atribuição própria "pelo trabalho de suplência para a função neurológica do cerebelo, deficiente" 16b (pág. 203 e fig. 19).

Do quadro neurológico - $\mathrm{Na}$ fenomenologia neurológica há pouco aqui descrita e em parte comentada ressaltam a incapacidade de equilíbrio, quer estático e segmentar - camptocormia - quer para a locomoção, bem como crises de hipertonia muscular de tipo cerebelar. A astasia-abasia constitui ocorrência freqüente em processos da convexidade frontal, dos quais não raro pode constituir o único indício, como o ilustra um caso clínico de Aloysio de Castro ${ }^{4}$ (págs. 22 e 23). Em relação ao paciente da atual observação anátomo-clínica, entretanto, a predominância de manifestações cerebelares e ao mesmo tempo a ausência da apraxia da marcha descrita por Brun ${ }^{3}$, bem como, principalmente, da apraxia de ação coordenada de Kleist ${ }^{13 a}$, excluíam o comprometimento do pólo frontal. Assim, dentre as síndromes topográficas frontais tão exaustivamente estudadas por Delmas-Marsalet ${ }^{5}$, estaria em causa apenas a de tipo profundo, da qual aliás participam os distúrbios abásico-astáticos. Semelhante síndrome porém não significa, para nós, apenas lesão direta da profundidade do lobo frontal - eventualidade em que surgiriam sintomas estranhos ao caso em aprêço ${ }^{19}$ (quadro I) mas também envolvimento das vias que estabelecem ligação com o cerebelo ${ }^{19}$ (pág. 30 e quadro IV). A hipótese de alterações cerebelares predominantes e a suspeita de etiologia tumoral para os distúrbios parecem em desacôrdo com o fato de alteraçōes dos fundos oculares estarem ausentes, em mais de um exame; entretanto, a estase papilar depende, como é corretamente aceito, de hidrocefalia interna; e esta pode faltar mesmo em processos pròpriamente neoplásticos da fossa posterior, até em fase adiantada ${ }^{10}$.

Aos distúrbios neurológicos denotados no caso do paciente correspondem, tanto em sentido funcional quanto sob o ângulo topístico, a zona orbitária do lobo frontal e de outro lado regiões neocerebelar e paleocerebelar, com predominância desta última. Assim o mostram as desordens motoras 
ou, de modo mais geral, neurológicas, as quais têm absorvido quase totalmente as verificações dos neurofisiologistas que se dedicam ao estudo do cerebelo. Também o evidenciam os transtornos psíquicos, a que logo nos referiremos, habitualmente esquecidos naquelas pesquisas.

Em relação ao dinamismo de regência, inconteste, que o cerebelo exerce sôbre a motilidade, há que distinguir prèviamente a diversa participação do paleocerebelo e do neocerebelo. Conforme acentua Fulton ${ }^{7}$, ao discutir minudentemente as verificações neurofisiológicas sôbre o cerebelo (págs. 463490) : "Seria de prever que as projeções piramidais, mediante as colaterais da ponte, teriam ligações primàriamente com o neocerebelo; e que as projeçōes extrapiramidais corticais, que influem sôbre o mecanismo postural, seriam associadas primàriamente ao lobo anterior e aos dinamismos paleocerebelares" (pág. 482). Daí advém, como é reconhecido clìnicamente e mesmo pela experimentação, que as alterações dos hemisférios cerebelares se traduzam pela chamada ataxia do tronco e que as do verme cerebelar acarretem abasia e perda paroxistica do tono muscular estático. No caso do paciente em aprêço, ambos os tipos de distúrbio estiveram presentes e entre êles a abasia foi dominante e progressiva. Éste particular clínico se explica pela situação mediana da massa principal de cisticercos. Fazemos notar ainda que não se apuraram sintomas característicos da falência neocerebelar: nem tremores ao iniciar movimento, nem dismetria, nem desordens adiadococinéticas.

Por outro lado, quanto à região cerebral interessada na síndrome, era a base do lobo frontal e não o pólo nem a convexidade que estava em causa. Efetivamente, tanto a convexidade quanto a zona orbitária da região frontal recebem influxos neocerebelares. Os distúrbios motores acentuados - com hiperatividade e inquietação - observados por Bianchi nas mutilaçōes da convexidade frontal ${ }^{2}$, foram também verificados na experimentação de Kennard e col.11, ${ }^{12}$ em macacos: hiperatividade e desigual amplitude da locomoção em cada membro, donde a "marcha circular" 11. Entretanto, Ruch e Shenkin demonstraram que tal ocorria devido a ser atingida nas experiências a área 13, e que esta de per si explicava o distúrbio ${ }^{15}$. Ademais, tanto clinicamente quanto na experimentaçāo, as lesões da corticalidade ou do pólo se exprimem por desordens psíquicas não apresentadas pelo paciente. Assim pudemos desde o início formular a hipótese localizatório-funcional de síndrome orbitária.

Ao contrário, os transtornos psíquicos em causa desde o início, uns progressivos, outros transitórios, confirmavam a diagnose topística. Insistimos nestes sintomas - intelectuais e conativos — porque ainda não se encontram satisfatỏriamente caracterizados na literatura psiquiátrica. Têm entretanto sido assinalados com relativa freqüência em observaçōes anátomoclinicas.

Distúrbios psíquicos -- Mesmo em relação à convexidade do lobo frontal os neurofisiologistas permaneceram durante muito tempo sob o domínio da falsa concepção de "zona muda". Entretanto, já no fim do sécuio passado 
Bianchi pôde desfazer êsse mito, utilizando as próprias experiências e revendo cs dados obtidos por outrem. A capacidade de distinguir entre alimentos e materiais não comestivels - função portanto tìpicamente intelectual - desaparecia nos animais cujas áreas frontais eram mutiladas ${ }^{2}$ : ao mesmo tempo que a inquietação motora, no plano neurológico, era necessário considerar aquêle transtôrno psíquico. Deficiência perfeitamente comparável a essa foi anotada em macacos, na experimentação de Kennard e Ectors, já referida ${ }^{11}$. E ainda, de modo mais sistemático, nas metódicas pesquisas de Jacobsen ${ }^{\circ}$ sôbre o papel dos lobos frontais no aprendizado dos primatas. Com maior razão ainda, pela ausência de satisfatória doutrina prévia, os autores em geral deixaram de reconhecer funçōes psíquicas à região orbitária do lobo frontal: e isso apesar de se registrarem na literatura observações clínico-anatômicas concludentes. Foi sòmente Kleist quem demonstrou de modo claro e preciso a existência de síndrome peculiar ao cérebro orbitário. Na arrojada carta funcional do cérebro ${ }^{13 a, 16 a, ~ b ~ e s t a b e l e c e ~}$ o conjunto de efeitos psíquicos peculiar à zona cíngulo-orbitária. Tais atributos, que arrolamos como conativos e instintivos $16 \mathrm{a}, 19$, devem ser distinguidos daqueles que constituem apanágio exclusivo da corticalidade: o pensa-

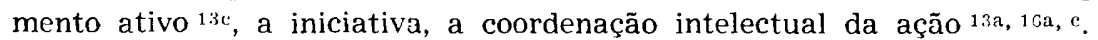

Coube a Leonora Welt, segundo precisa Kleist 13a, descrever em primeira mão alterações do caráter como conseqüência de lesões da região frontal orbitária. Caída em descrédito, essa importante verificação clínicopatológica de 1888 foi reabilitada e reavaliada pelo insigne mestre de Frankfurt am Main, que também lhe retificou a configuração clínica e lhe imprimiu fundamento doutrinário, baseado nas próprias observações pessoais 13a. Mostrou Kleist que nesses quadros, como na mória de Jastrowitz, há que distinguir sintomas pròpriamente orbitários e sintomas da corticalidade 16a, b, ou do tronco cerebral. Estariam em causa, nas lesões da região orbitária, fenômenos de déficit funcional da "personalidade", na acepção de Kleist. Tais distúrbios, quando na fase inicial, não são reconhecidos como tais nem pela família nem pelo médico, em geral, segundo o acentua Peter Duus ${ }^{6}$ muito judiciosamente: dai as contradições da literatura relativa ao lobo orbitário. Reunindo 30 casos de tumores da região orbitária, dos quais 5 de observação pessoal, Duus divide o quadro psiquiátrico orbitário em duas fases: inicialmente, alterações do caráter, marcadas e bem definidas, mas em regra interpretadas como "esquisitices" pelos circunstantes, durante meses e mesmo anos; no estágio final, carência de iniciativa que progressivamente atinge até o grau de espurcícia; como transição entre ambas podem ocorrer alucinações 6 (págs. 645-646).

Para compreender o porque desta sintomatologia e de que forma transtornos ne:uropsíquicos tão diversos podem indicar a mesma sede cerebral, é necessário considerar, ainda que ràpidamente, as concepções de Kleist sôbre as funçōes do lobo orbitário ou, melhor, da região cíngulo-orbitária. Aí se situam, segundo Kleist, as estruturas prepostas às várias manifestações da perscnalidade (Ichsphäre). Esta abrange três niveis ${ }^{13 \mathrm{~b}}$ : afetividade e instintividade (Gefühls- und Trieb-Ich), em plano inferior; personalidade so- 
mática (Körper-Ich), com as sensações internas, como estágio médio; em plano superior, o do caráter, a personalidade subjetiva, a sociabilidade (Selbst-, Gemeinschafts-Ich), a religiosidade (Welt- und religiöses Ich). Em outro passo ${ }^{13 a}$ (pág. 1250) acentua que todos êsses domínios da personalidade compreendem um lado sensorial e um lado motor: no primeiro caso e nessa ordem em que os enumeramos, sentimentos, momentos instintivos, sensações corporais, intenções (Gesinnungen); no outro, movimentos reativos, expressivos, instintivos (Trieb-) e desempenhos voluntários (Willensbetätigungen). E com relação ao aspecto localizatório 13a: " $O$ córtex do cíngulo e do cérebro orbitário contêm, portanto, provàvelmente um campo sensorial dos estímulos interoceptivos com tonalidade afetiva. Além disso ai vão ter impressóes olfativas oriundas da região olfativa, as quais poderiam cooperar nessas regiōes com as sensaçōes orais, anais, genitais e viscerais para a alimentação, a excreção e a procura sexual" (pág. 1165; grifos do original).

Esta participação da região orbitária na regência da vida vegetativa e mesmo de atividades instintivas foi depois demonstrada experimentalmente por Bailey e Sweet ${ }^{1}$ e por T. C. Ruch e H. A. Shenkin ${ }^{15}$, independentemente. $\mathrm{E}$ mesmo o aspecto mais subjetivo das manifestações instintivas, o emocional, pôde ser evidenciado em primatas nos quais Fulton e Ingraham ${ }^{8}$ produziram lesões limitadas à região orbitária.

Sob o aspecto clínico, as observações que se têm dedicado especificamente a êste gênero de perturbações neuropsiquiátricas revelam dados concordantes em relação aos distúrbios de origem orbitária. Kleist, que lhes dedica o estudo a um tempo mais minucioso, mais completo e mais sistemático, arrola nesta rubrica - "Os distúrbios das funções da personalidade e dependência para com o cérebro orbitário, o cingulo e o cérebro intermediário" 13a (págs. 1159-1254) — 39 observações pessoais de ferimentos de guerra. Compara-as com as similares de outros autores e completa-as com o próprio material clinico de lesões focais do cérebro. Como alterações de origem orbitária refere: a) no domínio da personalidade subjetiva e da sociabilidade, deficiência das intenções e das atitudes morais (gesinnungsmässige), bem como dos empreendimentos correspondentes (instabilidade); b) em relaçāo à noção de si próprio (Eigenerleben) - que envolve também feixes de ligação do lobo orbitário - transtornos da unidade da personalidade em sentido volitivo, donde a falta de empreendimento ou de liberdade de ação; c) no setor da instintividade, a deficiência de iniciativa - pelo comprometimento das ligações com a região frontal - e a falência dos instintos individuais em conseqüência dos distúrbios diencefálicos.

Duus, da escola de Kleist, assinala no estudo de conjunto que já citamos ${ }^{6}$ a transição dos transtornos psiquicos da fase de alteraçōes anti-sociais do caráter para a de embotamento completo, inclusive com espurcícia; além disso, distúrbios vegetativos na fase final, devidos porém à hipertensão endocraniana. Em alguns pacientes de nossa observação pessoal também foi registrada grave alteração do caráter, o que levou ao diagnóstico topográfico, confirmado depois pelos dados objetivos. 
Um dêstes doentes, sexagenário, faleceu aos dois meses de internação. Durante o periodo de observação revelou decadência mental progressiva e rápida, finalmente com embotamento global da inteligência e da iniciativa, inclusive com espurcícia ${ }^{17}$. Dois anos antes da internação denotava baixa da eficiência no trabalho e graves distúrbios do comportamento: faltas ao serviço, furto de utensílios da oficina, espancamento da espôsa, já acamada; tentativa de coito com a espôsa quase moribunda e agressões contra as pessoas presentes que o impediram, o que determinou intervenção da polícia e, a seguir, a internação. O quadro neuropsiquiátrico do lobo frontal se complicava com sintomas extrafrontais (apraxia, agrafia, distúrbios extrapiramidais, outros de tipo cerebelar) e os dados liquóricos denunciavam neoplasma endocraniano. Daí o diagnóstico localizatório quando da pneumencefalografia: "Provável neoplasia ao nivel da grande via fronto-cerebelar. Sindrome do lobo frontal, com repercussão sôbre a zona parietal inferior (agrafia, apraxia)" 19 (págs. 56-57, obs. 8 e fig. 20). O pneumencefalograma foi concordante; a necropsia revelou meningeoma paramediano ao nivel da região orbitária, o qual se acompanhava de edema do lobo frontal, com degeneração de feixes frontoparietais (Dr. Paulo Pinto Pupo) ${ }^{1 \top}$.

Dois outros internados do Hospital de Juqueri apresentaram o quadro orbitário não por neoplasma porém por aracnoidite optoquiasmática: nestes o quadro mental não exibia transtornos extrínsecos, os quais ocorrem nos tumores. Da súmula de observação neuropsiquiátrica de um dêles: "Orientação psíquica conservada"... “Acentuada lentidão no trabalho mental. Viscosidade intelectual. Fabulações ocasionais. Minuciosidade. Expressão sem desordens intrínsecas. Afetividade aparentemente embotada, de modo habitual. Periodos de grande destrutividade e agressividade, que diz inconscientes. Refere auto-mutilação e tentativa de suicídio, nas mesmas condições. Perversões instintivas, ao que diz." ..."Convulsões epileptiformes, que diz datarem dos 15 anos de idade. Convulsões e hipertonia muscular tìpicamente pitiáticas.” ... “Diagnóstico: Quadro psiquiátrico frontal-orbitário” 19 (pág. 56, obs. 7 e fig. 19; os grifos são desta transcrição). A verificação neurocirúrgica (Dr. A. de Mattos Pimenta) confirmou os dados neurooftalmológicos de aracnoidite opto-quiasmática. São algo diversas as desordens sumariadas em relação ao outro: "Orientação psíquica íntegra." ... "Trabalho mental rápido. Excitaçāo psíquica. Prolixidade. Por vêzes fabulações, de tipo mitomaníaco. Chistes, trocadilhos. Expressão sem distúrbios intrínsecos. Atividade prática desviada no sentido da superprodutividade dispersiva. Perversidade, de tipo da mória. Euforia pueril, discordante." ... "Diagnóstico: Desordens neuropsiquiátricas por aracnoidite optoquiasmática (quadro mental do lobo frontal, região orbitária)" 19 (pág. 57, obs. 9 e fig. 21; grifos da atual transcrição). Também aqui a inspeção neurocirúrgica ratificou o diagnóstico de aracnoidite opto-quiasmática (Dr. A. de Mattos Pimenta).

Valor topistico dos distúrbios - Alguns transtornos, tanto neurológicos quanto de ordem psiquica, ocorreram durante todo o período de observação e mesmo foram progressivos. Outros, porque transitórios ou cronológica- 
mente secundários, foram interpretados como fenômenos de repercussão, na acepção anteriormente discutida $16 \mathrm{~b}, 19$.

No primeiro caso, a ataxia do tronco, a astasia-abasia e a perda de equilíbrio faziam admitir alteração permanente ao nível da região paleocerebelar; crises de hipertonia muscular, não constantes, sugeriam exacerbação transitória dos distúrbios de regência; e a compensação neocortical cerebral se mostrava falha por ocasião dos surtos de tremores.

Quanto aos sintomas mentais, eram de natureza instintiva os mais constantes e se acentuaram progressivamente: alheiamento para com o ambiente e desinterêsse progressivo pelas próprias condições, o que atingiu o grau da espurcícia. A hiperemotividade, de aparência pitiática, foi evidente - e poderia falsear o diagnóstico, segundo dissemos - enquanto foi possivel o contato com o mundo subjetivo do examinando. A integridade habitual do trabalho intelectual, sujeito a erros de orientação alopsíquica compreensiveis ante a situação de internado, revelava que a região da convexidade frontal estaria indene. Como estados mórbidos transitórios na esfera intelectual, assinalamos momentos de obnubilação, os quais refletem a falência do dinamismo da vigília; tal dinamismo, segundo demonstrou Kleist ${ }^{13 a}$, filiável ao tronco cerebral, depende da função instintiva básica, a de nutrição (A. S.), por sua vez atribuída ao neocerebelo. Assim, a manutenção do esfôrço e da ativiḑade em geral, e a regência instintiva dos próprios atos, exibiam distúrbios caracterizados pelo déficit grave, no caso agora referido. Ambas as manifestações da personalidade, às quais Kleist designa, respectivamente, como Ausdauer e gesinnungsmässige Handlungen, constituem, com as exteriorizações do caráter — Gesinnungen - apanágio do córtex orbitário: vejam-se a carta funcional original em Gehirnpathologie 13a (fig. 429, à pág. 1365) e a versão brasileira, em que os têrmos correspondentes aparecem como Perseverança, atos intencionais, Caráter 16a (fig. 8, à pág. 145), (fig. 3 , à pág. 195 ${ }^{16 b}$. Esta última, a do caráter, esteve caracterizada também pela falência e não pela perversão como nas observações anátomo-clínicas há pouco referidas; ou então pelo comportamento teatral, misto de indiferença e de exibicionismo. De qualquer forma, como acentuamos, o quadro em conjunto passava para segundo plano em referência aos distúrbios paleocerebelares.

Este conjunto de considerações, que tivéramos em mente ao sopesar os transtornos neuropsiquiátricos sob critério patogênico ao mesmo tempo espacial e cronológico ${ }^{19}$ (págs. 28-30), levou nosso raciocínio clínico à diagnose de quadro frontal orbitário como conseqüência de alterações paleocerebelares.

\section{RESUMO}

$O$ paci€nte fôra âpresentado duas vêzes $\epsilon m$ reuniões clínicas, para diagnóstico diferencial entre alterações neuropsíquicas orgânicas e pitiatismo. Da primeira, aos 2 meses de internação, releva notar os seguintes dados: trabalho mental lento, porém sem distúrbios intelectuais intrínsecos; atenção 
pouco fixável; expressão verbal sem transtornos intrínsecos, mas escassa; carência global de iniciativa; indiferença para com a própria situação; atitudes por vêzes teatrais, em aparência pitiáticas; hipertonia muscular variável, aparentemente despertada pelo exame; marcha em pequenos passos, com incerteza variável; queda lenta, em direção inconstante; camptocormia, que se exagera quando desamparado; crises tônicas, de tipo da descerebração; condições somáticas precárias; exame neuro-oftalmológico só possível quanto a fundos oculares, sem anormalidade; exames de liquor incompletos, com alteraçōes discretas; reações negativas para sifilis no líquor e no sangue. Diagnóstico provisório: Psicose por lesão cerebral, com provável comprometimento orgânico da região frontal orbitária ou da via fronto-pontocerebelar.

Ao ser apresentado da segunda vez, decorridos três meses, estavam mais acentuados o desligamento para com o ambiente, a carência de iniciativa, a total incapacidade para cuidar de si, com espurcícia; agravou-se a perturbação da marcha com completa astasia-abasia e com ataxia do tronco; tornaram-se mais freqüentes as crises tônicas de tipo cerebelar; repetidos os exames de líquor, ainda incompletos, denotaram alterações do mesmo tipo anterior; o exame de fundos oculares foi novamente negativo; não fôra ainda possivel a pneumencefalografia. A evolução dos distúrbios, com alteraçōes de origem orgânica evidente e com outras aparentemente pitiáticas, permitiu precisar o aspecto localizatório: Síndrome frontal orbitária por alterações cerebelares prováveis.

Sòmente cinco meses após a primeira discussão clínica do quadro, quando obtido o exame completo do líquor, o diagnóstico etiológico pôde ser aventado. O exame neuro-oftalmológico foi ainda negativo. A evolução dos sintomas levou o doente à obnubilação e ao embotamento intelectuais, à espurcicia; e, pelo lado neurológico, à impossibilidade de locomoção, à ataxia do tronco, ao relaxamento dos esfincteres. Diagnóstico: quadro neuropsiquiátrico orbitário, como repercussão de alterações ponto-cerebelares; cisticercose provável.

O paciente faleceu 11 meses após a internação. A necropsia revelou, quanto ao sistema nervoso central, um cacho de vesículas de cisticerco racemoso ao nível do ângulo ponto-cerebelar direito (fig. 1) e espessamento das leptomeninges na base do encéfalo até a dos lobos temporais. Nenhuma alteração histológica do córtex cerebral ou das vias intra-hemisféricas (Nissl e Weil).

Quanto ao aspecto patogênico, o quadro orbitário descrito por Kleist era representado pela falência na manutenção do esfôrço e da atividade em geral (Ausdauer), na regência instintiva dos atos (gesinnungsmässige Handlungen), bem como pelo distúrbio teatral, tipo pitiático, do caráter (Gesinnung). Os transtornos neurológicos e mesmo neurovegetativos correspondiam, na cpinião dos autores, à falência paleocerebelar. 


\section{SUMMARY}

Clinical pattern of orbital lobe with cerebellar fits. Cysticercus racemosus of ponto-cerebellar region.

The patient had been shown twice in seminar for discussion of differential diagnosis between pithiatism and organic brain lesions. At first, two months after admission, the pattern was as follows: no peculiar troubles in thinking; impaired attention; poor spontaneous speech; general lack of initiative; no care for the self; behavior sometimes theatrical, apparently pithiatic; muscular hypertonia, aroused by the examination; gait uneaven, by short steps, subject falling often, in no predictable direction; tonic spells, decerebrate in type; poor bodily status. No neurophthalmic disorders (only the fundi examination was feasible, for lack in cooperation); mild alterations at the spinal fluid tests; tests for syphilis negative in the serum and in the spinal fluid. Provisional diagnosis: psychosis with brain lesions, probably in the orbital region or along fronto-ponto-cerebellar pathways.

At the second time, three months later, seclusion was growing worse, lack of undertaking was most marked, the patient was completely unable to care for himself and remained conspurcated; gait troubles were accrued with astasia-abasia and trunk ataxia; cerebellar fits were more frequent; fluid examinations, still incomplete, and neurophthalmic data gave no new results; pneumoencephalography was not yet available. The pattern of intermixed organic troubles and pithiatic behavior led to a closer pathogenetic diagnosis: orbital syndrome due to cerebellar lesions probably.

It was only five months after admission that proper fluid examination was available, and then rendered an etiologic diagnosis possible. The patient was then unable to walk and to take care of himself, and remained unalert. Diagnosis: neuropsychiatric orbital syndrome evoked by cerebellopontine disturbances; cysticercosis probably.

Exitus eleven months after admission. Necropsy disclosed, as for the c.n.s., a bunch of cysticercus racemosus at the cerebello-pontine region, at right (fig. 1); leptomeninges were somewhat thick at the basis until the temporal lobes. No alteration of the frontal lobes or elsewhere, macroscopically and histologically as well (at Nissl and Weil stains).

As for the pathogenesis, the orbital patterns, in sensu Kleist's, consisted of lack in maintaining mental alertness and the initiative (Ausdauer), in the instinctual drives (gesinnungsmässige Handlungen), as well as of the theatrical troubles of character (Gesinnung). Neurological and neuro-vegetative troubles were to be ascribed to paleo-cerebellar regulations, in the authors' mind.

\section{REFERENCIAS}

1. BAILEX, P.; SWEET, W. H. - Effects on respiration, blood pressure and gastric motility of stimulation of orbital surface of frontal lobe. J. Neurophysiol., 
3:276, 1940. 2. BIANCHI, L. - La Mécanique du Cerveau et les Fonctions des Lobes Frontaux. Arnette, Paris, 1921. 3. BRUN, R. - Zur Frage der Stirnhirnataxie: ein neues Stirnhirnsymptom. Z. Neurol., 138:122, 1932. 4. CASTRO, A. Notas e Observações Clínicas, $3^{*}$ série. Ponzini, São Paulo, 1943. 5. DELMAS-MARSALET, P. - Lobe frontal et équilibre. Encéphale, 31:15, 1936. 6. DUUS, P. Uber psychische Störungen bei Tumoren des Orbitalhirns. Arch. f. Psychiat., 109: 596, 1939. 7. FULTON, J. F. .-. Physiology of the Nervous System, 2nd ed. Oxford Press, Londres-Nova York-Toronto, 1943. 8. FULTON, J. F.; INGRAHAM, F. D. Emotional disturbances following experimental lesions of the base of the brain (pre-chiasmal). J. Physiol., 67:27, 1929. 9. JACOBSEN, C. F. - A study of cerebral functions in learning: the frontal lobes. J. Compar. Neurol., 52:271, 1931. 10. JUNQUEIRA FRANCO, G.; SILVEIRA, A. - Tumor do ângulo ponto-cerebelar com estase papilar tardia. Arq. Assist. Psicopatas de São Paulo, 1:77, 1936. 11. KENNARD, M.; ECTORS, L. - Forced circling in monkeys following lesions of the frontal lobes. J. Neurophysiol., 1:45, 1938. 12. KENNARD, M.; SPENCER, P.; FOUNTAIN, G. - Hyperactivity in monkeys following lesions in the frontal lobes. J. Neurophysiol., 4:507, 1941. 13. KLEIST, K. - a) Gehirnpathologie vornehmlich auf Grund der Kriegserfahrung. Barth, Leipzig, 1934; b) Leitvortrag über Gehirnpathologie und Klinik der Persönlichkeit. Arch. f. Psychiat., 103:301, 1935; c) Störungen des Denkens und ihre pathologische Grundlagen (paralogische und alogische Denk-Störung). In Roggenbaus Gegenwartsprobleme der psychiatrisch-neurologischen Forschung. Enke, Stuttgart, 1939. 14. PIMENTA, A. M.; SILVEIRA, A. - Importância dos feixes intracerebrais para o dinamismo psicopatológico. Congresso de Psiquiatria (Buenos Aires), 12-11-1944. 15. RUCH, T. C.; SHENKIN, H. A. - The relation of area 13 of the orbital surface of the frontal lobes to hyperactivity and hyperphagia in monkeys. J. Neurophysiol., 6:349, 1943. 16. SILVEIRA, A. - a) Campos arquitetônicos do lobo frontal e funções da inteligência. Rev. de Neurol. e Psiquiat. de São Paulo, 3:131, 1937; b) Lesōes casuais e lesões sistemáticas do cérebro nas doenças mentais. Arq. Assist. Psicop. de São Paulo, 2: 191, 1937; c) Importância das concepçōes localizatórias para a neuropsiquiatria e particularmente para a intervençāo no cérebro. Rev. de Neurol. e Psiquiat. de São Paulo, 4:154, 1938. 17. SILVEIRA, A.; PUPO, P. P. - Tumor cerebral da fossa anterior (meningioma paramediano) em doente sexagenário: observação clínica e anatōmica. Arq. Assist. Psicop. de São Paulo, 1:57, 1936. 18. SILVEIRA, A.; ROBORTELLA, M. - Sindromo frontal orbitário e sintomas cerebelares. Arq. Assist. Psicop. de São Paulo, 12:309, 1947. 19. SIlveIRA, A.; SIlvA, C. P.; ROBORTELLA, M. - Contribuição para a semiologia psiquiátrica: a pneumencefalografia. Arq. Assist. Psicop. de São Paulo, 12:5, 1947.

Rua Marconi, 53, 8० andar - São Paulo, Brasil. 